\title{
Delicaflavone induces apoptosis and autophagy, and improves the cytotoxicity of multiple myeloma cells to cisplatin by inactivating the AKT/mTOR pathway
}

\author{
Liangbo $\mathrm{Yi}^{1 *}$, Feifei Yang ${ }^{2}$, Zhonglu $\mathrm{Yi}^{2}$ \\ ${ }^{1}$ Department of Rehabilitation, Affiliated Hospital of Chifeng University, ${ }^{2}$ Department of General Practice, Southwest Village \\ Clinic, Xicheng Office, Hongshan District, Chifeng City, Inner Mongolia Autonomous Region 024000, China
}

*For correspondence: Email: Ibyi999@163.com; Tel: +86-04765973300

Sent for review: 8 February 2021

Revised accepted: 27 April 2021

\begin{abstract}
Purpose: To determine the effects of delicaflavone in multiple myeloma cells. Methods: Multiple myeloma cells were incubated with different concentrations of delicaflavone (20, 40, and $80 \mu \mathrm{M}$ ) or coincubated with $40 \mu \mathrm{M}$ delicaflavone and $20 \mu \mathrm{M}$ cisplatin. Cell viability and proliferation were investigated using MTT and colony formation assays, respectively. Flow cytometry and western blot analysis were applied to investigate cell apoptosis and autophagy.

Results: Treatment with delicaflavone decreased cell viability and proliferation of multiple myeloma cells but promoted cell apoptosis in a dose-dependent manner. Protein expression of Autophagy-related protein 7 (Atg7) and LC3-II/LC3-I were increased by delicaflavone treatment, while p62 was decreased by the same treatment. Delicaflavone also conferred cisplatin sensitivity in multiple myeloma cells through decreases in cell viability and in cell proliferation. AKT/mTOR phosphorylation was reduced in multiple myeloma cells treated with delicaflavone.

Conclusion: Delicaflavone induces apoptosis and autophagy of multiple myeloma cells, and confers cisplatin sensitivity through inactivation of the AKT/mTOR pathway.
\end{abstract}

Keywords: Delicaflavone, Apoptosis, Autophagy, AKT/mTOR, Multiple myeloma

\begin{abstract}
This is an Open Access article that uses a fund-ing model which does not charge readers or their institutions for access and distributed under the terms of the Creative Commons Attribution License (http://creativecommons.org/licenses/by/4.0) and the Budapest Open Access Initiative (http://www.budapestopenaccessinitiative.org/read), which permit unrestricted use, distribution, and reproduction in any medium, provided the original work is properly credited.
\end{abstract}

Tropical Journal of Pharmaceutical Research is indexed by Science Citation Index (SciSearch), Scopus, International Pharmaceutical Abstract, Chemical Abstracts, Embase, Index Copernicus, EBSCO, African Index Medicus, JournalSeek, Journal Citation Reports/Science Edition, Directory of Open Access Journals (DOAJ), African Journal Online, Bioline International, Open-J-Gate and Pharmacy Abstracts

\section{INTRODUCTION}

Multiple myeloma is a malignant tumor characterized by excessive proliferation of malignant plasma cells in the bone marrow [1,2]. Multiple myeloma is the second most common cancer of the hematological system, accounting for about $10 \%$ of all hematological malignancies [3]. Although a variety of pharmacological strategies have been developed for the treatment of patients with multiple myeloma, including the use of proteasome inhibitors, immunomodulators, and alkylating agents, numerous problems still occur in these patients, such as poor treatment outcome and poor prognosis [4]. Therefore, novel strategies to improve therapeutic efficacy are urgently needed for multiple myeloma patients.

Cisplatin is a chemotherapeutic drug that is widely used in the treatment of cancer [5]. It is 
also used to treat recurrent and refractory multiple myeloma [6]. However, tumors treated with cisplatin are prone to drug resistance, which greatly limits its application [7]. Drugs that confer cisplatin sensitivity in multiple myeloma cells would contribute to the treatment efficacy of cisplatin in multiple myeloma.

Delicaflavone is a biflavonoid found in Selaginella doederleinii Hieron [8]. A large number of studies have shown that delicaflavone exerts anti-tumor effects with excellent safety profiles. For example, Wensong Yao et al [9] found that delicaflavone promoted apoptosis of colorectal cancer cells and repressed colorectal cancer proliferation. Delicaflavone conferred cisplatin sensitivity in non-small cell lung cancer cells [10]. However, the effects of delicaflavone on multiple myeloma cell apoptosis, autophagy, and cisplatin resistance have not yet been reported.

This study investigated the effects of delicaflavone on the proliferation and apoptosis of multiple myeloma cells. Autophagy and cisplatin sensitivity of multiple myeloma cells were also investigated, and the downstream pathways were investigated using western blot analysis.

\section{EXPERIMENTAL}

\section{Cell culture and treatment}

Multiple myeloma cell lines (U266 and $\mathrm{NCl}$ H929) were purchased from ATCC (Rockville, MD, USA). The cells were cultured in RPMI 1640 (Gibco, Grand Island, NY, USA) containing $10 \%$ fetal bovine serum (Gibco) in a $37^{\circ} \mathrm{C}$ incubator. The cells were incubated with different concentrations of delicaflavone $(20,40$, or 80 $\mu \mathrm{M})$ for $48 \mathrm{~h}$. Delicaflavone was synthesized in the laboratory and confirmed by HPLC. The cells were coincubated with $40 \mu \mathrm{M}$ delicaflavone and $20 \mu \mathrm{M}$ cisplatin (Sigma-Aldrich, St. Louis, MO, USA) for $48 \mathrm{~h}$.

\section{Cell viability}

Multiple myeloma cells under delicaflavone or cisplatin treatment $(4,000$ cells/well) were seeded in 96-well culture plates for 24 hours, and then incubated with $10 \mu \mathrm{L}$ MTT stock solution (5 $\mathrm{mg} / \mathrm{mL}$; Sigma-Aldrich) for $4 \mathrm{~h}$. Dimethyl sulfoxide (150 $\mu \mathrm{L}$, Sigma-Aldrich) was added to each well, and absorbance at $450 \mathrm{~nm}$ was recorded with a microplate reader (Bio-Rad, Hercules, CA, USA). Cell viability (V) was calculated as in Eq 1.
$V(\%)=\{(A t-A b) /(A c-A b)\}$

where At, $A b$ and $A c$ are the absorbance of treatment, blank and control samples, respectively.

\section{Cell proliferation}

Multiple myeloma cells under delicaflavone or cisplatin treatment were seeded at a density of 500 cells/well into six-well culture plates. Two weeks later, the colonies in each well were fixed in methanol and stained with crystal violet before measurement under a light microscope (Olympus, Tokyo, Japan).

\section{Cell apoptosis}

Multiple myeloma cells under delicaflavone or cisplatin treatment were collected using trypsin digestion. Cells in binding buffer were stained with Annexin V-FITC/propidium iodide (Beyotime, Beijing, China) before analysis in a FACSCalibur flow cytometer (BD Biosciences, San Jose, CA, USA).

\section{Western blot assay}

Multiple myeloma cells were lysed in RIPA lysis buffer (Thermo Fisher Scientific, Waltham, MA, USA). Protein concentrations of the lysates were determined using the Bicinchoninic Acid Protein Assay Kit (CoWin Biotechnology, Beijing, China). Proteins in the lysates were separated using SDS-polyacrylamide gel electrophoresis and then transferred onto PVDF membranes (Merck Millipore, Darmstadt, Germany). Following blocking in $5 \%$ nonfat milk, the membranes were incubated with primary specific antibodies against Atg7 and p62 (1:2000; Santa Cruz Biotechnology, Santa Cruz, CA, USA), LC3-II and LC3-I (1:2500; Santa Cruz Biotechnology), AKT and p-AKT (1:3000; Santa Cruz Biotechnology), mTOR and p-mTOR (1:3500; Santa Cruz Biotechnology), and $\beta$-actin (1:4000; Santa Cruz Biotechnology) overnight at $4{ }^{\circ} \mathrm{C}$. The membranes were then incubated with horseradish peroxidase-conjugated antibodies (1:5000; Santa Cruz Biotechnology). Enhanced Chemiluminescence Detection kit (Thermo Fisher Scientific) was used to detect the immunoreactive bands on the membranes using a ChemiDoc ${ }^{\text {TM }}$ MP Imaging System (Bio-Rad).

\section{Statistical analysis}

All data are expressed as mean \pm standard deviation. Statistical comparisons were performed with Student's $t$-tests using GraphPad Prism 7.0 software (GraphPad Software, CA, 
USA). Values of $p<0.05$ were regarded as statistically significant.

\section{RESULTS}

\section{Delicaflavone repressed multiple myeloma cell proliferation}

To determine the effect of delicaflavone (Figure 1 A) on multiple myeloma progression, multiple myeloma cells (U266 and $\mathrm{NCl}-\mathrm{H} 929)$ were treated with different concentrations of delicaflavone. Cell viabilities of U266 and $\mathrm{NCl}$ H929 cells were reduced following delicaflavone treatment, in a dose-dependent manner (Figure 1 B). Delicaflavone treatment also suppressed proliferation of U266 and $\mathrm{NCl}-\mathrm{H} 929$ cells (Figure $1 \mathrm{C})$, suggesting that delicaflavone exerts an anti-proliferative effect against multiple myeloma.
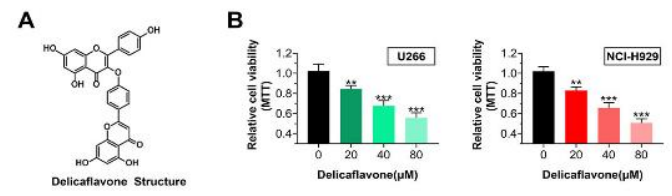

C

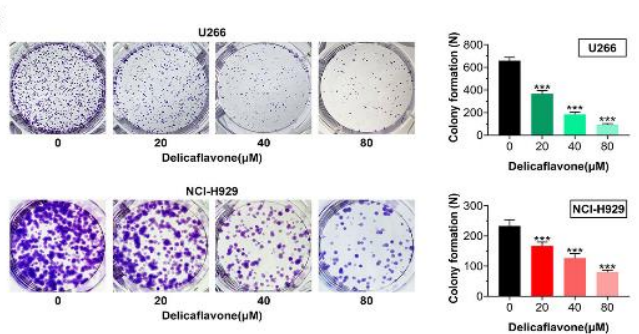

Figure 1: Delicaflavone suppressed multiple myeloma cell proliferation. (A) Chemical structure of delicaflavone. (B) Delicaflavone reduced cell viability of U266 and $\mathrm{NCl}-\mathrm{H} 929$ cells in a dose-dependent manner. (C) Delicaflavone suppressed proliferation of U266 and $\mathrm{NCl}-\mathrm{H} 929$ cells; ${ }^{* *} p<0.01,{ }^{* * *} p<0.001$

\section{Delicaflavone promoted multiple myeloma cell apoptosis}

In addition to the anti-proliferative effect of delicaflavone against multiple myeloma cells, its effect on multiple myeloma cell apoptosis was investigated by flow cytometry. Results showed that delicaflavone treatment promoted apoptosis of U266 and $\mathrm{NCl}-\mathrm{H} 929$ cells (Figure 2), suggesting the pro-apoptotic effect of delicaflavone against multiple myeloma.

\section{Delicaflavone promoted autophagy multiple myeloma cells}

The functional effect of delicaflavone on autophagy of multiple myeloma cells was investigated by western blot analysis. Results revealed that expression of p62 protein was reduced in $\mathrm{U} 266$ and $\mathrm{NCl}-\mathrm{H} 929$ cells following delicaflavone treatment (Figure 3). Atg7 levels and the LC3-II/LC3-I ratio were enhanced in U266 and $\mathrm{NCl}-\mathrm{H} 929$ cells after delicaflavone treatment (Figure 3), suggesting that autophagy of multiple myeloma cells was promoted by delicaflavone.
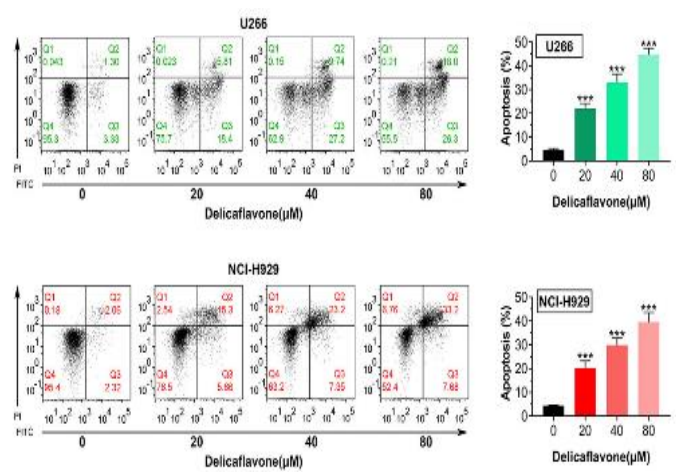

Figure 2: Delicaflavone promoted multiple myeloma cell apoptosis. Delicaflavone promoted apoptosis of U266 and NCl-H929 cells; ${ }^{* * *} p<0.001$

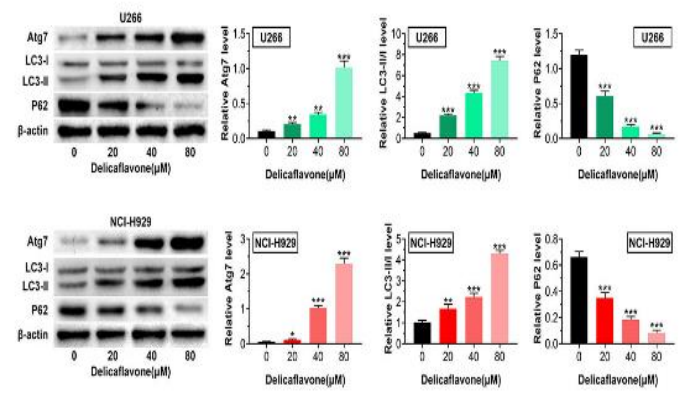

Figure 3: Delicaflavone promoted autophagy of multiple myeloma cells. Delicaflavone promoted protein expression of Atg7 and increased the LC3II/LC3-I ratio, while it decreased p62 expression, in U266 and NCl-H929 cells; ${ }^{*} p<0.05,{ }^{* *} p<0.01,{ }^{* * *} p<$ 0.001

\section{Delicaflavone enhanced cisplatin cytotoxicity in multiple myeloma cells}

To determine the effect of delicaflavone on drug resistance in multiple myeloma, U266 and $\mathrm{NCl}$ H929 cells were coincubated with delicaflavone and cisplatin. Cell viability was decreased by cisplatin treatment in both $\mathrm{U} 266$ and $\mathrm{NCl}-\mathrm{H} 929$ cells (Figure $4 \mathrm{~A}$ ), and delicaflavone treatment promoted the cisplatin-induced loss of cell viability (Figure 4 A). Similarly, cisplatin treatment suppressed the proliferation of $\mathrm{U} 266$ and $\mathrm{NCl}$ H929 cells (Figure 4 B), and delicaflavone treatment aggravated the suppression of cell proliferation by cisplatin (Figure $4 \mathrm{~B}$ ). These results demonstrated that delicaflavone 
conferred cisplatin sensitivity in multiple myeloma cells.

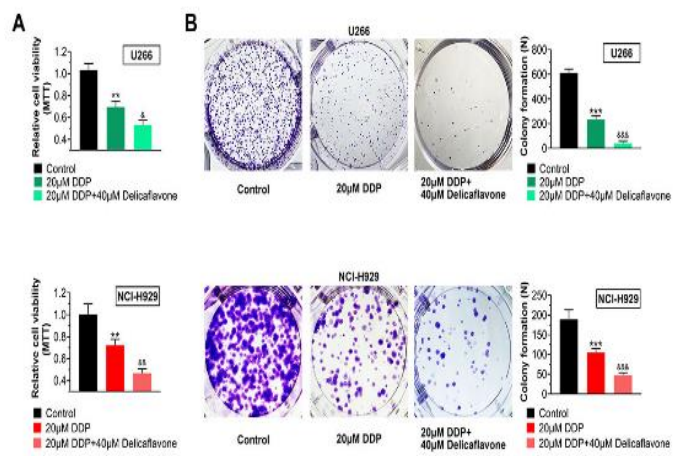

Figure 4: Delicaflavone improved cytotoxicity of cisplatin in multiple myeloma cells. (A) Delicaflavone treatment promoted the cisplatin-induced decrease in cell viability in U266 and $\mathrm{NCl}-\mathrm{H} 929$ cells. (B) Delicaflavone treatment aggravated the suppression of cell proliferation by cisplatin in $\mathrm{U} 266$ and $\mathrm{NCl}-\mathrm{H} 929$ cells; ${ }^{*} p<0.05,{ }^{* *}, \& \& p<0.01,{ }^{* * *} \& \& \& p<0.001$

\section{Delicaflavone suppressed activation of the AKT/mTOR pathway}

The downstream pathway involved in delicaflavone-mediated changes in multiple myeloma progression was investigated through western blot analysis. Results showed that delicaflavone treatment did not affect the expression of AKT or mTOR proteins in U266 and $\mathrm{NCl}-\mathrm{H} 929$ cells (Figure 5). However, phosphorylation of AKT and mTOR were reduced by delicaflavone treatment (Figure 5), indicating that delicaflavone inhibited multiple myeloma progression by suppressing activation of the AKT/mTOR pathway.
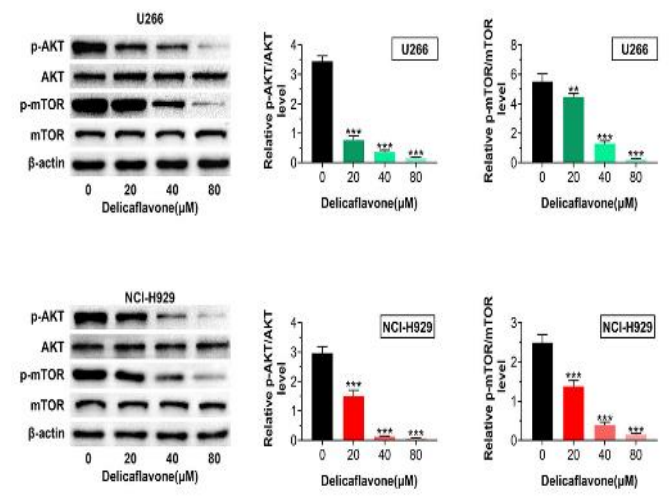

Figure 5: Delicaflavone suppressed activation of the AKT/mTOR pathway. Delicaflavone treatment dosedependently reduced phosphorylation of AKT and mTOR in U266 and NCl-H929 cells; ${ }^{*} p<0.01,{ }^{* * *} p<$ 0.001

\section{DISCUSSION}

Bioactive biflavonoids in medicinal plants demonstrate suppressive effects on tumor angiogenesis [11]. Delicaflavone, a biflavonoid found in Selaginella doederleinii Hieron, exerted an anti-tumor effect on colorectal cancer [9]. The roles of delicaflavone in multiple myeloma progression were investigated in the present study.

In this study, delicaflavone suppressed multiple myeloma progression, which was authenticated by several lines of evidence. Firstly, cell viability and proliferation of multiple myeloma cells were decreased by delicaflavone. Secondly, delicaflavone treatment promoted the apoptosis of multiple myeloma cells. Thirdly, delicaflavone treatment promoted autophagy of multiple myeloma cells. Autophagy maintains cellular homeostasis through protein quality control in the endoplasmic reticulum [12]. Dysregulated autophagy has been implicated in the pathogenesis of multiple myeloma [12]. Targeting autophagy has been shown to be a promising approach for regulation of multiple myeloma cell proliferation, apoptosis, and invasion [12].

Delicaflavone was reported to promote autophagy and cell apoptosis in lung cancer [13]. The results of our study showed that delicaflavone treatment decreased protein expression of p62, increased the level of autophagy-related protein 7 (Atg7), and increased the ratio of protein light chain 3 (LC3)II/LC3-I. Protein light chain 3 (LC3)-I in the nucleus and cytoplasm of normal cells and LC3-II in autophagosome membranes are forms of microtubule-associated protein 1 light chain 3, the specific marker of autophagy [14]. Autophagy-related protein 7 (Atg7) functions as an E1-like enzyme to convert LC3-I to LC3-II through lipidation [14]. Therefore, delicaflavone induces autophagic cell death in multiple myeloma. In addition to tumor metastasis and tumorigenesis, autophagy also mediates drug resistance in cancer therapies [15]. Mitophagy was inhibited in chemotherapy-resistant multiple myeloma cells [16]. Therefore, induction of autophagy might be helpful for the amelioration of drug resistance in multiple myeloma. Cisplatin resistance in non-small cell lung cancer cells was reversed by delicaflavone [10]. The present study indicated that delicaflavone conferred cisplatin sensitivity in multiple myeloma cells via decreases in both cell viability and proliferation. Autophagy also induces multi-drug resistance, leading to cytoprotective effects against anticancer therapy-induced responses [17], suggesting that suppression of autophagy could 
resensitize cancer cells to anticancer therapies. Because delicaflavone has been shown to resensitize cancer cells by mediating a pathway signaling endoplasmic reticulum stress [10], we then investigated the mechanism underlying delicaflavone-mediated autophagy and drug resistance in multiple myeloma cells.

The PI3K/AKT/mTOR pathway is the main regulator of autophagy during tumorigenesis and drug resistance [18]. Autophagy blockade promoted cell death in malignant peripheral nerve sheath tumors through inhibition of $\mathrm{PI3K} / \mathrm{mTOR}$ [19]. The suppressive role of delicaflavone on the AKT/mTOR pathway has been reported earlier [9,13]. AKT/mTOR phosphorylation was suppressed in multiple myeloma cells by delicaflavone in the present study, suggesting that delicaflavone might induce apoptosis, promote autophagy, and improve the susceptibility of multiple myeloma cells to cisplatin cytotoxicity through inactivation of the AKT/mTOR pathway.

\section{CONCLUSION}

Overall, this study indicates that delicaflavone protects against multiple myeloma by promoting cell apoptosis, autophagy, and drug sensitivity via inactivation of the AKT/mTOR pathway. This study suggests a potential therapeutic strategy for multiple myeloma. However, there is a need to investigate the role of delicaflavone in multiple myeloma cell growth in vivo.

\section{DECLARATIONS}

\section{Conflict of interest}

No conflict of interest is associated with this work.

\section{Contribution of authors}

We declare that this work was done by the authors named in this article and all liabilities pertaining to claims relating to the content of this article will be borne by the authors. Liangbo Yi designed the study and supervised the data collection, Feifei Yang analyzed and interpreted the data, and Zhonglu Yi prepared the manuscript for publication and reviewed the draft of the manuscript. All authors have read and approved the manuscript.

\section{Open Access}

This is an Open Access article that uses a funding model which does not charge readers or their institutions for access and distributed under the terms of the Creative Commons Attribution License (http://creativecommons.org/licenses/by/ 4.0) and the Budapest Open Access Initiative (http://www.budapestopenaccessinitiative.org/rea d), which permit unrestricted use, distribution, and reproduction in any medium, provided the original work is properly credited.

\section{REFERENCES}

1. Sachpekidis C, Goldschmidt H, Dimitrakopoulou-Strauss A. Positron Emission Tomography (PET) Radiopharmaceuticals in Multiple Myeloma. Molecules 2020; 25(1): 134.

2. Wang $Y$, Ji D, Chen G. MiR-379 inhibits proliferation and induces apoptosis in multiple myeloma by targeting $Y$ box binding protein 1. Trop J Pharm Res 2020; 19(9): 1843-1849.

3. Wang $X$, Xie H, Zhang L. Multiple myeloma with onset of pancreas involvement: A case report. Medicine 2019; 98(30).

4. Rajkumar SV, Kumar S. Multiple Myeloma: Diagnosis and Treatment. Mayo Clinic Proceedings 2016; 91(1): 101-119.

5. Wu T-H, Chang S-Y, Shih $Y-L$, Huang $T-W$, Chang $H$, Lin $Y-W$. Emetine Synergizes with Cisplatin to Enhance Anti-Cancer Efficacy against Lung Cancer Cells. Int J Mol Sci 2019; 20(23): 5914.

6. Park S, Lee SJ, Jung CW, Jang JH, Kim SJ, Kim WS, Kim K. DCEP for relapsed or refractory multiple myeloma after therapy with novel agents. Ann Hematol 2014; 93(1): 99-105.

7. Amable L. Cisplatin resistance and opportunities for precision medicine. Pharmacol Res 2016; 106: 27-36.

8. Sui $Y, L i S$, Shi $P, W u Y, L i Y$, Chen W, Huang L, Yao H, Lin $X$. Ethyl acetate extract from Selaginella doederleinii Hieron inhibits the growth of human lung cancer cells A549 via caspase-dependent apoptosis pathway. J Ethnopharmacol 2016; 190: 261-271.

9. Yao W, Lin Z, Shi P, Chen B, Wang G, Huang J, Sui $Y$, Liu Q, Li S, Lin $X$ et al. Delicaflavone induces ROSmediated apoptosis and inhibits PI3K/AKT/mTOR and Ras/MEKJErk signaling pathways in colorectal cancer cells. Biochem Pharmacol 2020; 171: 113680.

10. Wang X, Chen B, Xu D, Li Z, Sui Y, Lin X. Delicaflavone Reverses Cisplatin Resistance via Endoplasmic Reticulum Stress Signaling Pathway in Non-Small Cell Lung Cancer Cells. Oncotargets Ther 2020;13;1031510322.

11. Pang X, Yi T, Yi Z, Cho SG, Qu W, Pinkaew D, Fujise K, Liu M. Morelloflavone, a Biflavonoid, Inhibits Tumor Angiogenesis by Targeting Rho GTPases and Extracellular Signal-Regulated Kinase Signaling Pathways. Cancer Res 2009; 69(2): 518-525.

12. Ho M, Patel A, Hanley C, Murphy A, McSweeney $T$, Zhang L, McCann A, O'Gorman P, Bianchi G. Exploiting 
autophagy in multiple myeloma. J Cancer Metast Treat 2019; 5: 70.

13. Sui Y, Yao H, Li S, Jin L, Shi P, Li Z, Wang G, Lin S, Wu $Y$, Li Y et al. Delicaflavone induces autophagic cell death in lung cancer via Akt/mTOR/p70S6K signaling pathway. J Mol Med 2016; 95(3): 311-322.

14. Liang $C$, Feng $P, K u B$, Dotan I, Canaani D, Oh B-H, Jung JU. Autophagic and tumour suppressor activity of a novel Beclin1-binding protein UVRAG. Nat Cell Biol 2006; 8(7): 688-698.

15. Yun CW, Jeon J, Go G, Lee JH, Lee SH. The Dual Role of Autophagy in Cancer Development and a Therapeutic Strategy for Cancer by Targeting Autophagy. Int J Mol Sci 2021; 22(1): 179.

16. Zheng Z, Fan S, Zheng J, Huang W, Gasparetto C, Chao $\mathrm{N}$, Hu J, Kang Y. Inhibition of thioredoxin activates mitophagy and overcomes adaptive bortezomib resistance in multiple myeloma. J Hematol Oncol 2018; 11: 1-15.

17. Taylor MA, Das BC, Ray SK. Targeting autophagy for combating chemoresistance and radioresistance in glioblastoma. Apoptosis 2018; 23(11): 563-575.

18. Usman RM, Razzaq F, Akbar A, Farooqui AA, Iftikhar A, Latif A, Hassan H, Zhao J, Carew JS, Nawrocki ST et al. Role and mechanism of autophagy-regulating factors in tumorigenesis and drug resistance. Asia-Pac J Clin Onco 2020.

19. Ghadimi MP, Lopez G, Torres KE, Belousov R, Young ED, Liu J, Brewer KJ, Hoffman A, Lusby K, Lazar AJ et al. Targeting the PI3K/mTOR Axis, Alone and in Combination with Autophagy Blockade, for the Treatment of Malignant Peripheral Nerve Sheath Tumors. Mol Cancer Ther 2012; 11(8): 1758. 